\title{
Using centrifuge research in analysing stability of dikes
}

\author{
H.G.B. Allersma \\ Associate professor, Facuity of Civil Engineering \\ Delft University of Technology, the Netherlands
}

Synopsis: Centrifuge test are described to investigate the behavior of embankments, which protects land against flooding. The stability of dikes on soft soils and the behavior of dikes during widening and infiltration of water have to be known in order to predict the safety of the protection. Test have to be performed to investigate the failure mechanism and to examine the reliability of calculation methods. In a centrifuge the phenomena can be simulated rather easily and the test can be reproduced. It can be tested at what hight failure will occur when a sand dike is built on clay, several widening procedures can be: simulated and the water table in the dike can be manipulated. Parameters like pore water pressure and deformations can be measured in flight and can be used to control the test.

\section{Introduction}

Centrifuge research is a world wide accepted method to investigate the behavior of soil structures. A useful application is the validation of calculation methods and to visualise mechanisms. Furthermore several geotechnical problems cannot be solved at all by mathematics at this moment, so that experimental research is the only possibility to get insight in a particuiar geotechnical phenomenon.

In a centrifuge also in a small model a good ratio can be obtained between shear stresses and cohesion. Due to this condition small scale tests can be performed on clay models. Furthermore the stress dependent behavior of sand can be scaled in a correct manner. Usually calculation methods are validated by predicting the behavior of real scale problems. However, in reality the geometry is often rather complicated and the soil characterization contains several uncertainties, so that the validation has to be carried out on a complex problem. In centrifuge models, however, there can be made a start with simple configurations and the soil parameters are much better under control, so that a better connection with the theory is obtained. Because the models can be reproduced accurately, differences in behavior due to slight changes in the construction procedure can be made visible. For mechanism studies a small centrifuge is preferred, because models can be built in a short time and several tests can be performed due to the low costs of operation.

The applications of centrifuge research to coastal engineering in the Geotechnical Laboratory of the University of Delft are devoted to the behavior of embankments, which protects the land against floods. The stability of dikes on soft soils and the resistance of dikes against infiltration of water are of interest to predict the safety of the protection. Furthermore several dikes have to be improved by making them wider and higher. To prevent uncontrolled deformations this process of improvement have to be performed 


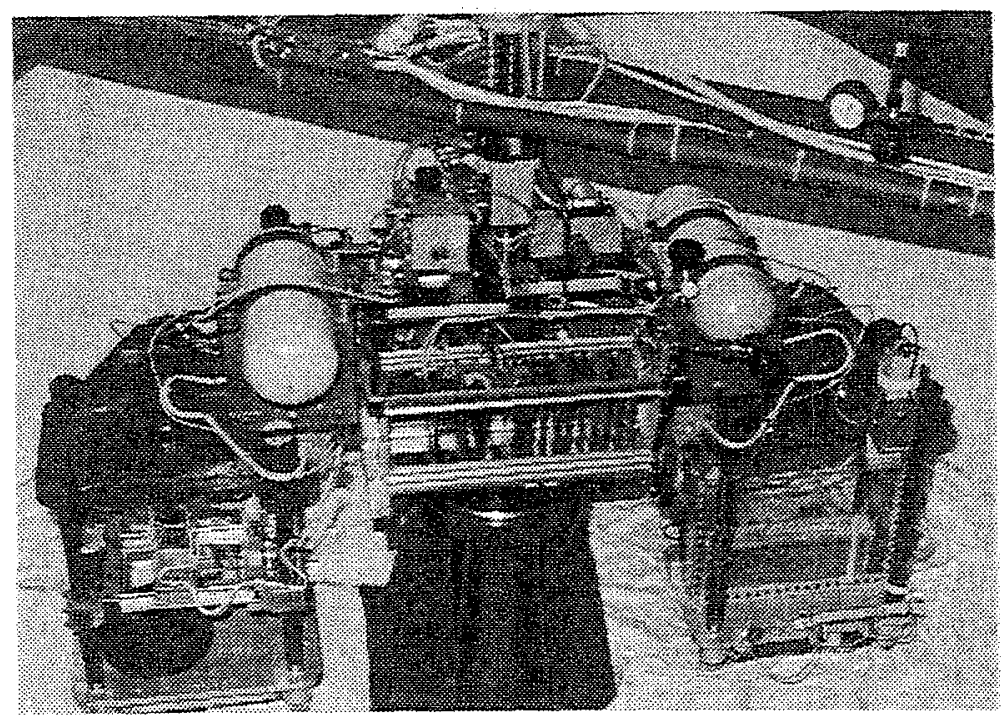

Fig.1. The University of Delft geotechnical centrifuge.

under well defined conditions. Very little centrifuge research has been done on the widening of embankments. Most of the embankments investigated in a centrifuge were stabilized by reinforcement (Almeida et al., 1985) or founded on consolidated clay (Davies et al. 1986). In the Netherlands, however, several embankments have to be founded on soft soils, so that an additional test program was required to investigate the behavior of this material.

In a centrifuge the phenomena can be simulated rather easily. It can be tested at what hight failure will occure when a sand dike is built on clay. Several widening procedures can be simulated, so that the behavior of the dike under different conditions can be observed. Parameters like pore pressure and deformations can be measured in flight and can be used in a test to control the widening procedure, just as what is used in practise. The behavior of a sand dike during infiltration can be tested. In a centrifuge test the cohesion due to capillarity can be reduced, so that the same ratio with the shear stresses is obtained as in the prototype problem. Because the capillar rising of the water is also in good proportion to the prototype dimensions the water flow trough the dike can be made visible by means of labels and the mechanism of failure can be visualised.

If the mechanisms of failure are known it is better possible to design methods which improves the stability. In many cases new methods can be tested rather easily in a centrifuge model to investigate the effect. Examples are the use of drains to improve the stability during infiltration.

\section{Test facilities}

\subsection{The centrifuge}

The tests are performed in a small geotechnical centrifuge (figure.1). This device has been developed at the Geotechnical Laboratory of the Faculty of Civil Engineering of the University of Delft (Allersma, 1994c). The design concept was to obtain a device which is flexible and cheap in operation. The centrifuge, which has a diameter of 2.4 meters, contains two swinging platforms to carry the samples. With the present motor power, 
samples with a weight of more than $300 \mathrm{~N}$ and a volume of $15 \times 40 \times 40 \mathrm{~cm}$ can be accelerated up to 150 times earth's gravity. In most cases the weight of the model containers is less than $200 \mathrm{~N}$, so that they can be handled by one person. This means that the centrifuge is very convenient in use. An advanced electronic system, containing a single-board IBM PC compatible computer (486 central processor, $66 \mathrm{Mh} z$ ), is installed in the spinning part of the centrifuge in order to control the tests. The computer can be accessed in a normal way via slip rings. A link with the mechanical devices is made by means of an analog to digital converter with a 16 channel multiplexer, two voltage controlled outputs of more than 5 Ampere each and two 16 bits counters.

A special feature is that several phenomena can be measured by using the video images of the on-board camera. Digital image processing is used to visualize and digitize automatically the surface deformation of clay and sand samples (Allersma, 1990). The deformation of the clay is made visible by means of a grid, which is copied to the clay surface. Several devices have been developed in order to perform tests in flight (Allersma, 1994a). In this test program, a computer controlled sand supply system and a water circulation system is used to manipulate the course of the test. A vane apparatus is used to determine parameters of the clay layer in flight. Miniature pressure sensors are used to measure the overburden pore water pressure during the widening of the embankment.

\subsection{In flight test equipment}

The following miniature devices have been used to perform in flight tests on embankments: Sand sprinkler; Water supply system; Vane apparatus

\section{Sand sprinkler}

A computer controlled sand sprinkler has been developed in order to make embankments in flight. Embankments with a height of approximately $60 \mathrm{~mm}$ can be built over a distance of $150 \mathrm{~mm}$. The device has proven to be reliable at more than $120 \mathrm{~g}$. Several options can be accessed in the control program. It is possible to sprinkle sand layer by layer or at one particular location. The control program of the sand sprinkler also reads the output of pressure transducers, which can be placed in the clay layer. The pore water pressure is plotted on the screen.

\section{Vane apparatus}

During flight parameters of the clay can be measured by a vane apparatus. The device has been automated in such a way that the depth ( range $100 \mathrm{~mm}$ ) can be adjusted in flight. The horizontal position of the vane can be adjusted over a range of $250 \mathrm{~mm}$ during flight, so that several tests can be performed without stopping the centrifuge. A complete test procedure can be defined in advance in the control program.

\section{Water supply system}

Water is circulated by means of a gas jet. In this technique the gas supply system is used to control the jet. The advantage of this system is that the water supply can be controlled very smooth from zero to the maximum flow and the system is very simple, at least if the air supply system is already available. The flow rate is detected by a small turbine. A maximum flow of about $10 \mathrm{l} / \mathrm{min}$ can been obtained. 


\subsection{Sample preparation}

An important requirement is that the soil samples can be reproduced in a very accurate way. Two different devices have been developed to prepare clay and sand layers. In order to visualize the slight differences in widening methods the preparation of the clay layer was of particular importance. Up to now it was found that the best control over the samples was obtained by making artificial clay. In this technique clay powder is mixed with water, where the air content is kept as low as possible. A technique has been developed in which an air free slurry is obtained under normal atmospheric conditions. The principle of the device is that the clay is added in a thin layer to the water, so that no air is included due to differences in capillarity. The best way to make clay with a smooth gradient of water content and strength over the height of the sample is to consolidate the slurry in the centrifuge at the same $g$ level as will be used in the tests. The consolidation will take several days when a low permeable clay is used. Therefore a special centrifuge has been built which is only used to consolidate the clay layers.

\section{Description tests}

\subsection{Test program}

A test program was carried out in the small geotechnical centrifuge of the University of Delft to investigate the effect of different methods of widening of embankments founded on soft soil. In the first instance only tests are carried out on kaolin (Allersma et.al., 1994b). In a new research project, however, also a natural clay was used as test material. Most tests are performed on a clay layer with a thickness of approximately 0.07 $\mathrm{m}$. At $100 \mathrm{~g}$ the same shear stresses can be simulated as in clay layer of 7 meters. Different methods of widening were simulated, where also the excess pore water pressure was taken into account. In centrifuge tests the same pore water pressure can be generated as in reality. Because the real dimensions of the model are hundred times smaller than the prototype problem the consolidation time is reduced by the square of the artificial gravity. The soil parameters were determined by laboratory tests, such as compression tests and triaxial tests, and in flight vane tests. These latter tests were also used to investigate whether the clay was homogeneous and whether all clay samples had the same strength. To validate the soil parameters found and to investigate whether the clay model behaved as expected, embankment tests were performed. From these embankment tests the maximum embankment height was found. To investigate the two widening methods, several tests were performed. The pore pressure measurements were used to determine the waiting time between the construction of the different layers.

\subsection{Embankments}

Embankment tests were performed to determine the maximum height of an embankment on a layer of clay. The embankment was made in flight, at $100 \mathrm{~g}$, by means of the computer controlled pouring device. After the sample was fully consolidated in the centrifuge, the sand was dropped at some place. In this way the slope of the embankment appeared to be $30^{\circ}$. The sand was dropped until the clay collapsed. Since this procedure took less than one minute, the test can be considered to be performed under undrained conditions. The slip circles could be well observed by the grid that was made on the clay. In figure 2 the slip circle can be seen, which go almost through the centre of the 


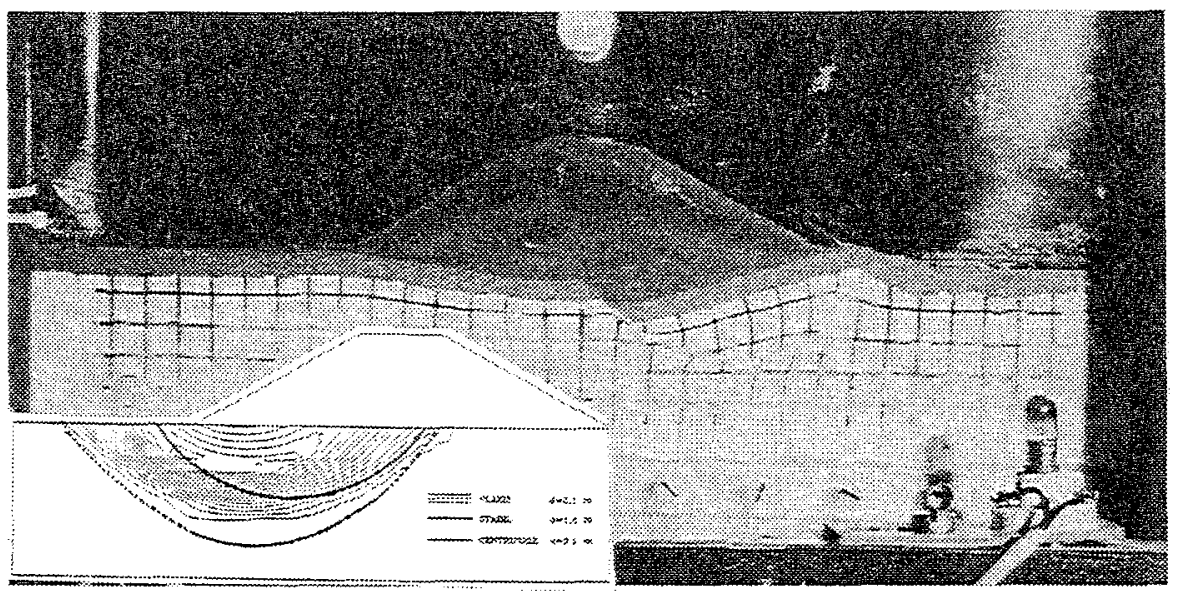

Fig.2. Stability test $\operatorname{fo}$ an embankment on normally consolidated kaolin.

embankment. This is in rather good agreement with the Bishop theory. The maximum height was found to be $0.043 \mathrm{~m}$, which is 4.3 meters in reality. The safety factor of this embankment calculated with the Bishop's method and numerically was 0.77 and 0.86 , respectively. From the embankment tests it can be concluded that the centrifuge tests give realistic results. However, it appeared that the determination of the soil parameters is very important. In these tests it was found that the parameters determined with the triaxial apparatus gave better results than those of the in flight vane apparatus.

\subsection{Widening of embankments}

The widening test are performed at $100 \mathrm{~g}$ on a clay layer with a thickness of $0.07 \mathrm{~m}$ and embankments heights of approximately $0.04 \mathrm{~m}$. This agrees with a prototype condition of $7 \mathrm{~m}$ clay and an embankment with a height of 4 meters. Two different types of clay were used; Kaolin and a Dutch natural clay. Two different methods to widen embankments were investigated and compared, i.e. the horizontal-method and the gapmethod. In the horizontal-method the widening is made of horizontal layers. In the gapmethod first a new embankment is constructed at some distance from the existing embankment and the gap is then filled. These tests were performed to investigate the existence of differences in the deformations of the existing embankments and if in some way they could be made visible. Those deformations, especially horizontal displacements, can be the cause of cracks in the asphalt which covers a dike.

The existing embankment was made at $1 \mathrm{~g}$, and had a height of $0.04 \mathrm{~m}$. Beads were placed in the embankment to be able to follow the deformations. On the clay layer a grid was copied to be able to follow the deformations. Two pore pressure transducers were placed in the clay layer, one located where the top of the widening would come and one under the existing embankment. After the clay layer was fully consolidated, the widening process was started. The widening part had a maximum height of $0.05 \mathrm{~m}$, depending on the drainage during the test.

The pore pressure readings were used to determine the waiting time between the application of the different layers. The waiting time was 1500 to 2000 seconds, which is 173 to 230 days in reality. 

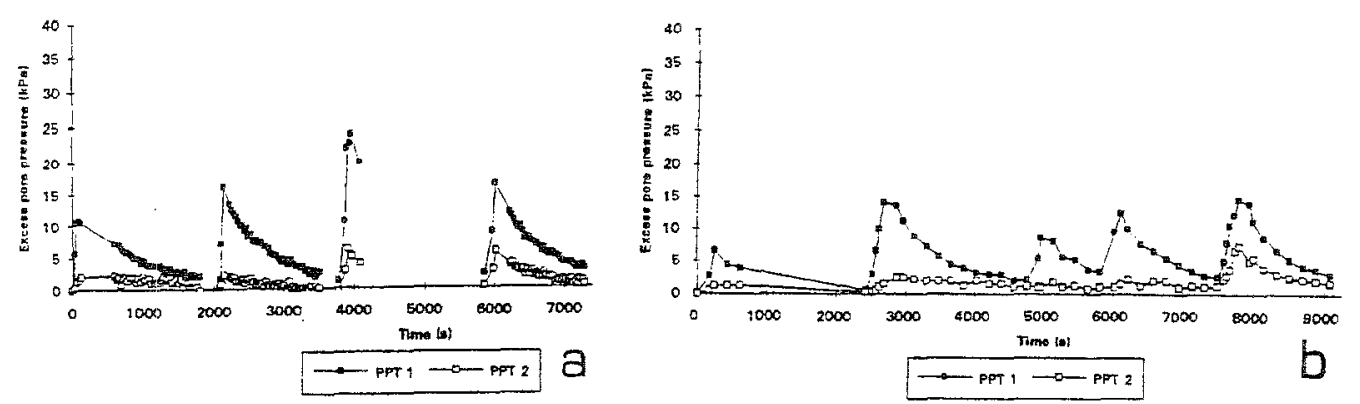

Fig.3. Measured pore pressure during widening, each peak represents a new layer (a new layer was supplied after $100 \%$ consolidation: a) horizontal method; b) gap method.
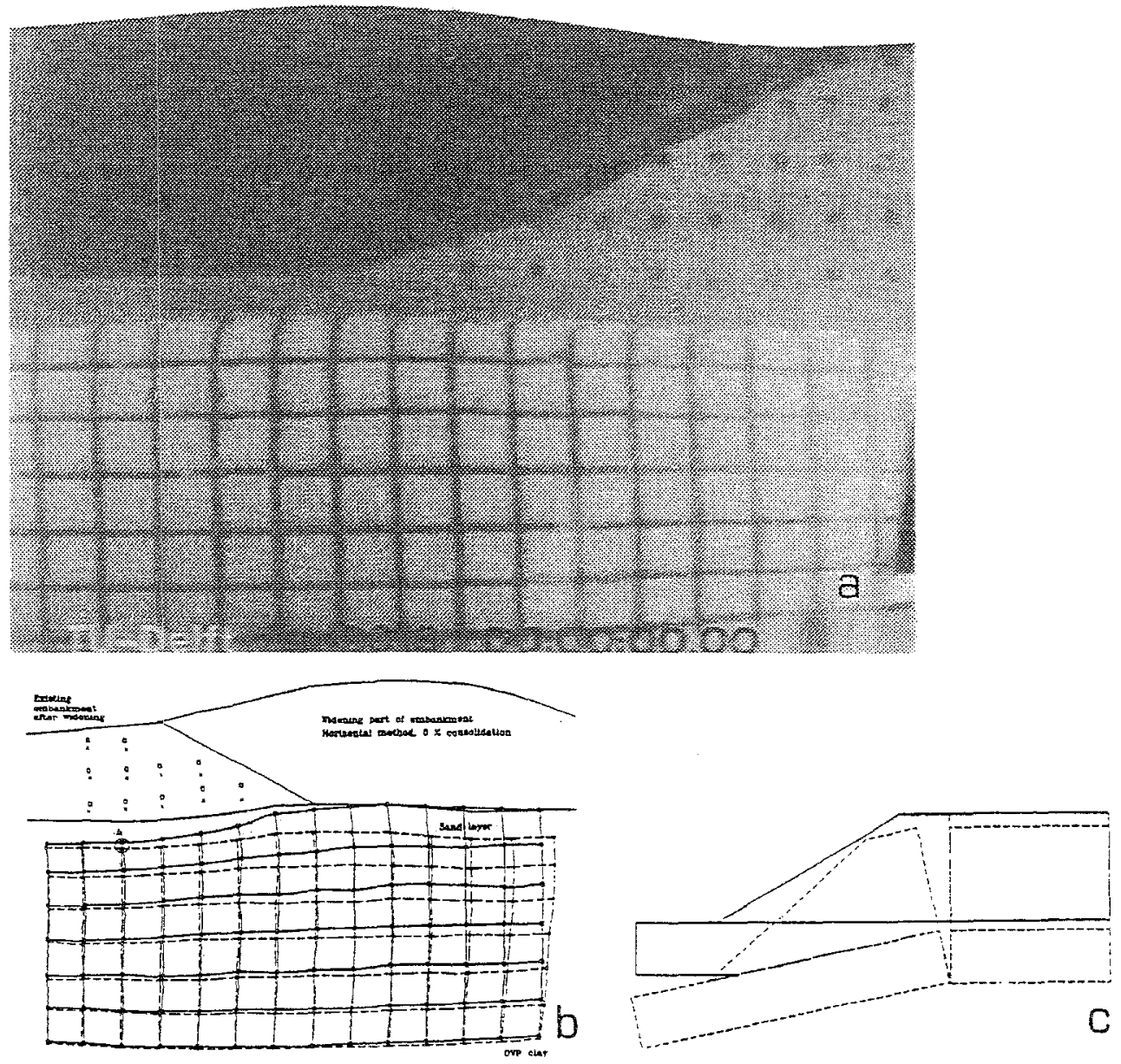

Fig.4. a) Photograph of the observed area of the widening tests. b) Graphical presentation of the optically measured displacements. c) Schematically presented mechanism.

In figure 3 the excess pore pressures for the two widening test can be seen. After the suppletion of the first layer, the next layers was only supplied after a reduction of the excess pore pressures to almost zero. This process was repeated for the next layers. The fifth peak that can be seen in figure $3 b$ was the filling of the gap. The pore pressure transducer 1 (PPT 1) was located under the new embankment and the PPT 2 was located 




Fig.5. Behavior of a sand layer, subjected to bending.

under the slope of the existing embankment.

With the help of image processing, the displacements of the nodes of the grid on the clay layer and the displacements of the beads in the existing embankment can be measured. In figure $4 \mathrm{~b}$ the displacement fields of a tests is visualized by processing the grid on the clay layer of two test stages by image processing. It was found that the difference of vertical displacements at the toe of the existing embankment and more to the centre were larger for the horizontal-method than for the gap-method. From this phenomenon a mechanism can be deduced as presented schematically in figure $4 \mathrm{c}$. The gradient for natural clay at different widening procedures is given in degrees in table 1 . The differences are only a few degree, it has to be realised however, that 3 degree can cause a crack of more than $25 \mathrm{~cm}$ at the surface of an embankment with a height of 5 meters if the mechanism of figure $4 \mathrm{c}$ is assumed. The gradient in the vertical displacement decreases when the clay was consolidated fully after each supplied layer of sand.

In figure 5 a sand embankment is tested, were the gradient in the vertical displacement is simulated by a hinged platform. It is demonstrated with this test that at a close distance the sand follows the motion of the platform. At higher levels, however, the sand seems to be forgotten what the initial deformation was, because strong local gradients in vertical displacements of the grid lines can be observed.

\begin{tabular}{|l|r|r|}
\hline horizontal method, & $0 \%$ cons. & $\alpha=3.2^{\circ}$ \\
horizontal method, $100 \%$ cons. & $\alpha=2.6^{\circ}$ \\
gap method, & $0 \%$ cons. & $\alpha=1.3^{\circ}$ \\
gap method, & $100 \%$ cons. & $\alpha=0.4^{\circ}$ \\
\hline
\end{tabular}

Table 1 Gradient in the vertical displacement using different widening methods. 


\subsection{Water infiltration}

In 1953 several dikes, which protect the low-lying parts of the Netherlands against the sea, were broken during a heavy storm in combination with spring tide. It appeared that several dikes were not damaged in the first instance on the sea side by the mechanical forces of the waves, but on the land side. The water of the sea had reached such a high level that it flowed over the top of the dikes due to the wave action. The water infiltrates into the dike, because the top of the dike and the slope on the land side were not covered with a waterproof layer. The water flow in the soil reduces the stability of the slope on the land side, which causes failure of the dike. Centrifuge tests have been performed to get more insight into the mechanism which causes failure. In a previous test program (Allersma et al., 1994d) clay dikes which are made higher by sand are tested. in a later test program more attention was paid to homogeneous dikes of sand which are covered with a clay layer. The stream lines are made visible and methods are tested which can improve the stability.

The tests are performed in plane boxes with transparent walls at a distance of $50 \mathrm{~mm}$ apart. The dimension of the box is $36 \times 40 \mathrm{~cm}^{2}$. The model of a dike was located on a metal platform. The space which was left under the platform was used as a water reservoir. A simple pump driven by compressed air was used to circulate the water.

Dikes of approximately 2 to 7 meters were simulated. The water was supplied at the top of the dike through a small box with a filter bottom to distribute the water equally. The water table in the sand layer was visible due to the difference in contrast between wet and dry sand. The stream lines are visualised by means of a tracer.

Due to the higher $g$ level the stresses, induced by the capillary forces $(36 \mathrm{~cm}$ water at 1 g) could be ignored. On the other hand the flow rate of the pore water in the dune sand during tests at $80 \mathrm{~g}$ was still low enough (maximum flow rate in the test series was 0.016 $\mathrm{m} / \mathrm{s}$ ) to keep the Reynolds number (the estimated max. value was 1.6) below the value which indicates turbulence (Goodings, 1984). If the flow can be assumed to be steady state and laminar, the flow rate of the water is linear with the acceleration of the centrifuge. Special tests have been shown that Darcy's law is valid at the higher acceleration level.

The aim of this test program was to investigate the mechanism which leads to failure of sand dikes which are covered with clay, during water infiltration. Furthermore methods are tested which could improve the stability and the effect of homogeinities are examined. The slopes are made of dune sand, characterized by

$\begin{array}{ll}\text { Unit weight } & 16 \mathrm{kN} / \mathrm{m}^{3} \\ \text { Permeability } & 0.01 \mathrm{~cm} / \mathrm{s} \\ \mathrm{D}_{10} & 0.1 \mathrm{~mm} \\ \mathrm{D}_{50} & 0.2 \mathrm{~mm}\end{array}$

Friction angle $36^{\circ}$

If a homogeneous dike of sand with a critical slope is infiltrated in the centrifuge, than the failure of the dike started near the toe due to local instability caused by seepage. The initial failure of a homogeneous dike appeared to be a surface phenomenon. Up to now no test show a Bishop like shear band mechanism. The local instability proceeds with increasing water flow, which results finally in a total failure of the embankment. If the sand slope is covered with a clay layer the first visible sign of failure is the crack in the clay layer (figure 6). This is caused by the fact that the clay layer is lifted up, so that the friction between clay and the sand slope is reduced to zero. Due to the own weight a crack comes in. The moment of uplift of the clay layer can be deduced from curvature of the visualised stream lines. It appeared that the crack in the clay layer is located at a 


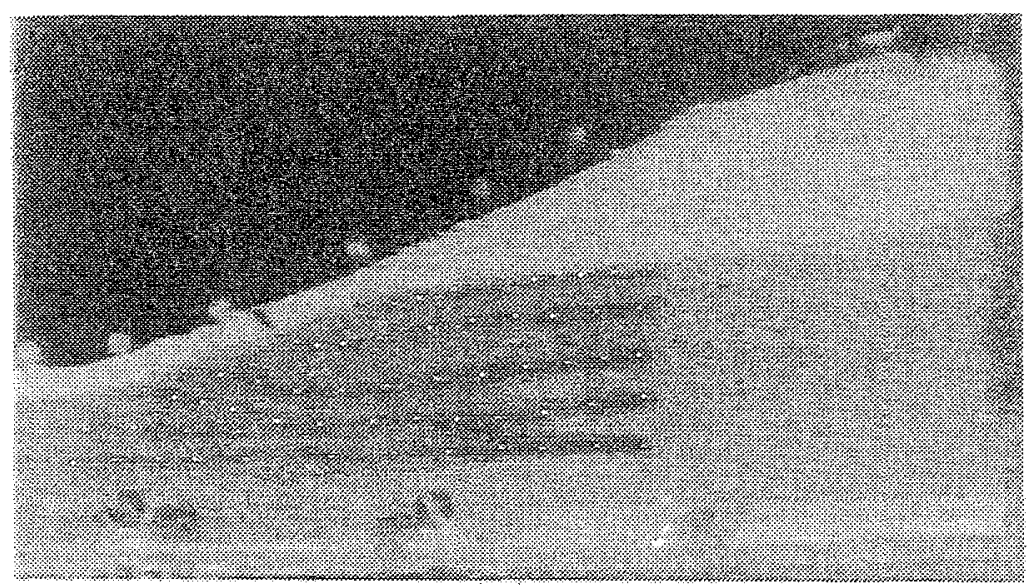

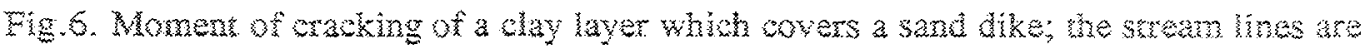
visualised by mens of a tracer.

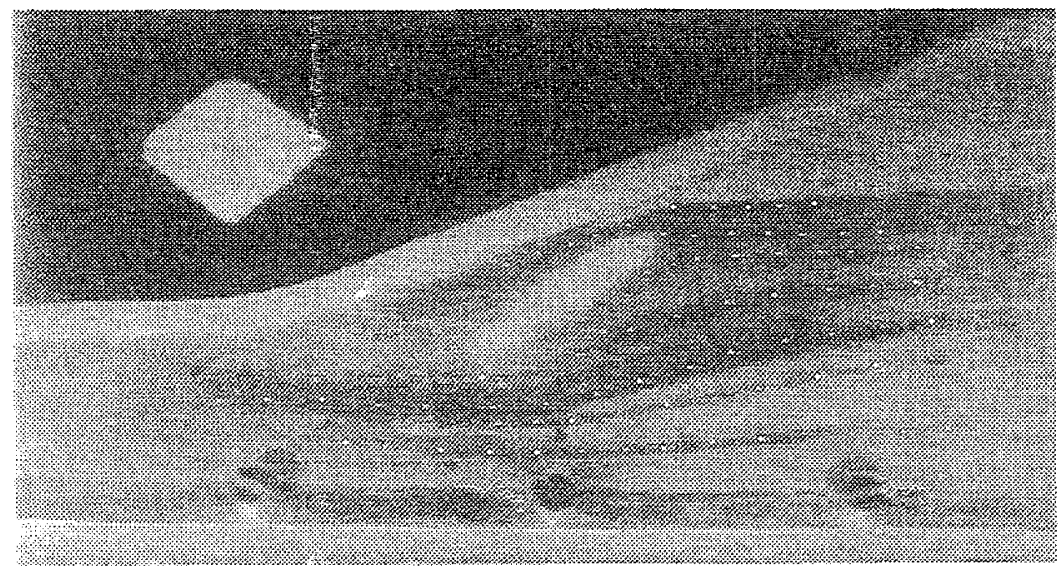

Fig.7. Effect of an inhomogeinity during infiltration.

higher position when the thickness of the layer increases.

The influence of a drain close to the toe of the dike could be tested also. As was expected more water was required to cause failure. In figure 7 the effect of a heterogeneity in the sand body is visualised. It was found that a heterogeneity can have a positive effect on the stability. In practice the water supply by wave overtopping is given in litres $/ \mathrm{s} / \mathrm{m}$. In these tests the water infiltration at failure varies between 0.1 and $0.31 / \mathrm{s} / \mathrm{m}$. There are no accurate measurements available from practice. In the design rules the permitted quantities lies between 0.1 and $10 \mathrm{l} / \mathrm{s} / \mathrm{m}$, depending on the protection of the slope.

\section{Conclusions}

The small geotechnical centrifuge was very convenient for investigating the stability of embankments. In a relatively short time a large number of test conditions could be investigated, were the costs are very reasonable.

The widening tests show very clear what mechanism causes horizontal deformations at the surface of the original embankment. It could be made visible that the horizontal deformation (bending) is dependent on the procedure of the sand suppletion. It was found 
that a smooth gradient in the vertical displacement in the sub soil can cause strong gradients in the vertical displacement at the surface of an embankment.

The moment of failure of a sand dike during wave overtopping is dependent on the degree of saturation and the slope angle of the sand body. Critical slopes with an angle of $36^{\circ}$ show failure if the phreatic line has reached the soil surface at a height of $1 / 3$ of the slope. Non-critical slopes can be completely saturated before failure occurs. It appeared that the failure of sand dikes during water infiltration at the crest is initiated by local instability due to seepage. This is in contradiction with some theoretical hypotheses, which assume that failure starts with a slip circle mechanism, like Bishop. In the centrifuge tests the behavior of a clay layer, which covers an embankment of sand could be visualised. Furthermore it could be demonstrated that the effect of a drain or an inclusion can be visualised by means of this test technique. It is believed that a small centrifuge is very valuable for testing new ideas in geotechnical engineering.

\section{Acknowledgement}

The described research is assisted by several graduate students from different countries, they are: L. Ravenswaay, L.A.G. Ligtenberg (the Netherlands), M. Borup, J. R. Hedegaard (Denmark), O. Mareschal (Belgium). Many thanks are devoted to the technicians of the laboratory for their assistance in this project. Some research projects are sponsored by the Ministry of Public Works.

\section{References}

Allersma, H.G.B.,1990: On line measurement of soil deformation in centrifuge tests by image processing. Proc. Int. Conf. on Experimental Mech., Copenhagen, pp.1739-1748. Allersma, H.G.B., 1991: Using image processing in centrifuge research. Proc. Int. Conf. Centrifuge91, Boulder, Balkema, Rotterdam, pp. 551-558.

Allersma, H.G.B., 1994a: Development of miniature equipment for a small geotechnical centrifuge. Transportation Research Record no.1432, Innovation in Instrumentation and Data Acquisition Systems, National Academy Press, Washington, D.C.,pp. 99-105.

Allersma, H.G.B., L. Ravenswaay, E. Vos, 1994b: Investigation on widening of roads on soft soil in a small centrifuge. Transportation Research Record no.1462, Compaction of difficult soils and resilient modulus testing, National Academy Press, Washington, D.C.,pp. 47-53.

Allersma, H.G.B., 1994c: The University of Delft geotechnical centrifuge. Proc. Int. Conf. Centrifuge94, Balkema, Rotterdam,pp.47-52.

Allersma, H.G.B., I.A.G. Ligtenberg, B.A.N. Koehorst, 1994d: Simulation of failure of dikes by water infiltration by waves. Proc. Int. Conf. Centrifuge94, Balkema, Rotterdam, pp. 289-294.

Goodings, D.J., 1984: Relationships for modelling water effects in geotechnical centrifuge models. Proc. Symp. Application of Centrifuge Modelling to Geotechnical Design, Manchester: 1-24.

Almeida M.S.S., R.H.G. Parry, 1985: Centrifuge Studies of Embankment Foundations strengthened with Granular Columns, Third Int. Geotechnical Seminar, Singapore.

Davies M.C.R., R.H.G. Parry, Centrifuge Modelling of Embankments on Clay Foundations, Soils and Foundations, Vol, 25, No. 24, 1986, pp 19-36 